\title{
Beneficial effects of cyclophosphamide on the relapse rate, duration of remission and the clinical state of the disease in patients with frequently relapsing nephrotic syndrome
}

\author{
U K Jayantha ${ }^{1}$ \\ Sri Lanka Journal of Child Health, 2007; 36: 133-4
}

(Key words: cyclophosphamide, relapse rate, remission, frequently relapsing nephrotic syndrome)

\begin{abstract}
Objective To find out the beneficial effects of oral cyclophosphamide in patients with frequently relapsing nephrotic syndrome.

Design Prospective study

Setting: University paediatric unit, Galle

Method Patients presenting with frequently relapsing, steroid sensitive nephrotic syndrome were included. Patients were given an 8 week course of oral cyclophosphamide $(2.5 \mathrm{mg} / \mathrm{kg} /$ day $)$. Number of relapses before and after cyclophosphamide therapy, duration of remission and state of the disease were recorded.
\end{abstract}

Results There were 17 patients included in the study (male 10, female 07). Mean age of onset of the disease was 35.2 months $(\mathrm{SD} \pm$ 4.3). Mean relapse rate before cyclophosphamide therapy was 4.5 per year $(\mathrm{SD} \pm 1.2)$. Mean relapse rate after cyclophosphamide therapy was 1.1 per year $(\mathrm{SD} \pm$ $0.9)$. This decrease in relapse rate was statistically highly significant $(\mathrm{P}<0.0001)$. Mean duration of remission after cyclophosphamide therapy was 20 months ( $\mathrm{SD} \pm 4.8)$. Subsequently 9 patients became infrequent relapsers and were managed with a standard steroid regime. One child became steroid dependent and 2 remained as frequent relapsers. Seven children were lost to follow up.

Conclusion Cyclophosphamide is a better alternative drug to steroids in patients with relapsing nephrotic syndrome.

\section{Introduction}

Nephrotic syndrome is not uncommon in childhood. Incidence in Asian countries is about 12-14 per 100,000 children and $70 \%$ suffer a relapsing course ${ }^{1}$. Frequently relapsing nephrotic

${ }^{1}$ Senior Lecturer in Paediatrics, Faculty of Medicine, Galle.

(Received on 8 February 2007; Accepted after revision on 29 February 2007) syndrome, in which the rate of relapses is 4 or more per year, is difficult to manage. According to the literature, prolongation of the initial steroid therapy beyond 8 weeks reduces the rate of subsequent relapses and the proportion of patients developing frequent relapses ${ }^{2,3}$.

Oral cyclophosphamide was initially used in the treatment of patients with poorly responding nephrotic syndrome in $1963^{4}$. Since then cyclophosphamide is being used in children with frequently relapsing, steroid dependent and steroid resistant types of nephrotic syndrome. There is no agreement on the precise stage at which alternative treatment to corticosteroids should be introduced. Major side effects of cyclophosphamide include haemorrhagic cystitis, bone marrow suppression and the risk of secondary malignancies. Cyclophosphamide metabolites are active and show toxic side effects on the urothelium. Toxic side effects are more frequently seen in children with renal insufficiency than in children with normal renal function. Hence it is advisable to maintain a good urine output in those patients receiving cyclophosphamide therapy.

\section{Method}

Patients presenting with frequently relapsing nephrotic syndrome were included in the study. Remission of proteinuria was induced with prednisolone $\quad 60 \mathrm{mg} / \mathrm{m}^{2} /$ day. Then cyclophosphamide $2.5 \mathrm{mg} / \mathrm{kg}$ /day was given as a single daily dose with prednisolone $20 \mathrm{mg} / \mathrm{m}^{2}$ every other day. Cyclophosphamide was continued for 8 weeks. Full blood count and urine for microscopic haematuria were checked weekly. Age of presentation, number of relapses before and after cyclophosphamide therapy, duration of remission after cyclophosphamide therapy and the clinical state of the disease were documented. Written consent was obtained from the parents before the commencement of oral cyclophosphamide therapy. Ethical approval was obtained from the Ethics committee of the Faculty of Medicine, Galle. 


\section{Results}

There were 17 patients included in the study of whom 10 were boys. Mean age of onset of nephrotic syndrome was $35.2 \pm 4.3$ months. Duration of follow up was 24-72 months. All patients were followed up for 24 months and 10 patients were followed up for a further 48 months. Seven patients dropped out after 24 months. Mean duration of remission was $20 \pm 4.8$ months. Mean relapse rate before cyclophosphamide was $4.5 \pm 1.2 /$ yr. Mean relapse rate after cyclophosphamide was $1.1 \pm 0.9 / \mathrm{yr}$. The drop of the relapse rate was statistically highly significant $(\mathrm{p}>0.0001)$

At 2-7 years of follow up there were 7 patients with infrequently relapsing disease and they were well managed with short courses of steroids while only 2 remained as frequent relapsers. One child became steroid dependent and 7 were lost to follow up. Side effects of cyclophosphamide encountered were alopecia (09), transient neutropenia (02), macroscopic haematuria (01) and microscopic haematuria (03).

\section{Discussion}

The proportion of frequently relapsing nephrotic syndrome was $20 \%$ among long term followed up patients with steroid sensitive nephrotic syndrome ${ }^{5}$. In patients with frequently relapsing nephrotic syndrome, steroid toxicity may develop with hypertension, cataract, growth failure and obesity; hence these children may require alternative therapy $^{6}$. Cyclophosphamide is the most commonly used drug as an alternative treatment. Results of this study have shown that oral cyclophosphamide therapy has reduced the relapse rate significantly up to the $25 \%$ of the previous value while causing prolongation of the duration of remission.

\section{Conclusion}

A course of cyclophosphamide is a better alternative to steroids in the management of frequently relapsing nephrotic syndrome.

\section{References}

1. Hodson EM, Knight JF, Willis NS. Corticosteroid therapy in nephrotic syndrome Arch Dis Child 2000; 83: 45 - 51.

2. Bagga A, Hari P, Srivastara R N. Prolonged versus standard prednisolone therapy for initial episode of nephrotic syndrome. Paediat. Nephrol 1999: 13: 824-7.

3. Jayantha UK. Prolonged versus standard course of steroid therapy for children with relapsing course of nephrotic syndrome. Paediat Nephrol 2004;19: C 99.

4. Barraat TM, Soothil JF, Controlled trial of cyclophosphamide in steroid sensitive relapsing course of nephrotic syndrome. Lancet 1970; 2: 479.

5. Jayantha UK. Steroid therapy in nephrotic syndrome. S.C. Paul Oration. Sri Lanka Medical Association 2004.

6. Brodehl J. Management of nephrotic syndrome in children. Clin Immune therapy 1996; 5:17592. 
